\title{
Effect of oestrogen therapy on faecal incontinence in postmenopausal women: a systematic review
}

\author{
Fiona L. Bach ${ }^{1,2}$ (D) B. Zeyah F. Sairally ${ }^{1} \cdot$ Pallavi Latthe $^{1}$ \\ Received: 13 October 2019 / Accepted: 29 January 2020 / Published online: 4 March 2020 \\ (C) The Author(s) 2020
}

\begin{abstract}
Introduction and hypothesis Faecal incontinence (FI) is prevalent in postmenopausal women. Oestrogen receptors have been identified in the anal sphincter and have been implicated in the pathogenesis and potential treatment. We sought to evaluate the literature regarding the impact of local and systemic oestrogen therapy on FI in postmenopausal women.

Methods A systematic review of all studies in postmenopausal women was performed to establish how oestrogen therapy affects FI. Eight articles were deemed eligible for inclusion following the Preferred Reporting Items for Systematic Reviews and MetaAnalyses (PRISMA) guidelines. Their quality was assessed using the Cochrane risk-of-bias tool (RoB-2) and Newcastle--Ottawa quality assessment scale.

Results One randomised controlled trial (RCT), two cohort studies, one observational and four cross-sectional studies were identified. The RCT showed an improvement in FI with anal oestrogen $(p=0.002)$, but this improvement was also observed in the placebo arm $(p=0.013)$ and no difference was seen between these groups. A prospective observational study demonstrated significant improvement with an oestrogen patch $(p=0.004)$, but had no control group. Conversely, a large prospective cohort study demonstrated an increased hazard ratio of FI with current (1.32; 95\% CI, 1.20-1.45) and previous oestrogen use (1.26; $95 \%$ CI, 1.18-1.34) compared with non-users.

Conclusion All studies had a high risk of bias and had conflicting views on the effects of oestrogen on FI in postmenopausal women. This review has identified the need for further research in this area by highlighting the paucity of good research for evidence-based practice. We believe that a further RCT of local oestrogen is mandated to draw a valid conclusion.
\end{abstract}

Keywords Oestrogen therapy · Faecal incontinence $\cdot$ Postmenopausal $\cdot$ Systematic review $\cdot$ Hormone replacement therapy Accidental bowel leakage

\section{Abbreviations}

AI Anal incontinence

FI Faecal incontinence

HRT Hormone replacement therapy

MHT Menopausal hormone therapy

OASI Obstetric anal sphincter injury

Oral presentation at BSUG Annual Research Meeting, London, November 2018

Fiona L. Bach

fionabach@yahoo.com

1 Birmingham Women's Hospital, Mindelsohn Way, Birmingham B15 2TG, UK

2 The University of Birmingham, Edgbaston Birmingham B15 2TT, UK
PICO Population, intervention, comparator and outcome

QoL Quality of life

RCT Randomised controlled trial

RR Relative risk

\section{Introduction}

Faecal incontinence (FI) in adults is a debilitating symptom that can severely impact quality of life (QoL) and represents a significant socioeconomic burden on the population [1]. It is likely to be underreported by patients owing to the social stigma associated with it. Variable definitions and the heterogeneous study populations make it difficult to establish the true incidence. A systematic review by $\mathrm{Ng}$ et al., which included 38 studies, found the prevalence to range from 2 to $21 \%$ for community-based adult females [2]. 
The pathogenesis of FI in postmenopausal women is likely to be multifactorial [3], but risk factors include injury of the obstetric anal sphincter (OASI) or the pudendal nerve during childbirth, increasing age [2] and pelvic floor changes secondary to menopause [4]. Oestrogen may be implicated and several studies have assessed the expression of sex hormone receptors in the bowel continence mechanism. Haadem et al., Oettling et al. and Parés et al. found oestrogen receptors in anal sphincter samples [5-7]. But in contrast, Rizk et al. did not identify oestrogen receptors in the rectal mucosa for either premenopausal or postmenopausal women [8]. Knudsen et al. found that female rats who had undergone a bilateral oophorectomy had a reduction in cross-sectional area of striated muscle of the anal sphincters compared with controls [9], suggesting a hormonal influence. It is known that lack of oestrogen after menopause contributes to the genitourinary symptoms of menopause, such as vaginal atrophy, urinary incontinence, recurrent urinary tract infections and dyspareunia and these have successfully been treated with local oestrogen therapy [10-13]. There is conflicting opinion as to whether oestrogen contributes to or protects from FI.

The objective of this review was to synthesise all the available evidence on the relationship between local and systemic oestrogen therapy and faecal incontinence in postmenopausal women.

\section{Materials and methods}

We performed a systematic review of all studies in female humans without any language restrictions.

\section{Eligibility criteria}

The population of interest was postmenopausal women, the intervention was the use of oestrogen therapy via any route, the comparator was no oestrogen use, placebo or other therapy and the outcome was faecal incontinence. All studies dealing with the above-mentioned population, intervention, comparator and outcome (PICO) of interest were evaluated.

\section{Search strategy and selection of studies}

A literature search of the bibliographic databases including Ovid, Medline , Cochrane library, EMBASE, LILACS, Global Index Medicus and Cumulative Index to Nursing and Allied Health Literature (CINAHL) was conducted by a professional librarian. The search strategy was based on a number of relevant medical subheadings (MeSH), words and word variants. The following key words were used: "menopause" or "postmenopause" AND "oestrogen replacement therapy" or "HRT" or "oestrogen" or "hormone" and "replacement" and "therapy" or "oestrogen only" or "combined" and "oestrogen" and "progesterone" AND "faecal incontinence" or "faeces" or "bowel" or "anal" and "incontinence".

The reference lists of the identified articles were searched and a grey literature search was performed to identify any other relevant articles or presentations (Annual Meetings screened for potential articles of interest: International Urogynecological Association [IUGA] 2014-2018 and International Continence Society [ICS] 2014-2017 [2018 not available]). Two reviewers then independently screened the titles and abstracts of all the articles and any disagreements were resolved through discussion or if required, by an independent third reviewer (PL). Full texts of the potentially eligible articles were then reviewed and assessed. One paper, only available in Portuguese, was translated into English for assessment.

The included studies were assessed for risk of bias using the Revised Cochrane risk-of-bias tool (RoB-2) [14] and the Newcastle-Ottawa quality assessment scale [15] where appropriate. The data were extracted independently by the two reviewers and entered onto a Microsoft Word table.

\section{Results}

A total of 148 articles were identified through the literature search. Twenty-nine full-text articles were retrieved and eight studies published between 1997 and 2017 were included in the final analysis. The selection of the articles has been reported in the Preferred Reporting Items for Systematic Reviews and Meta-Analyses (PRISMA) diagram (Fig. 1). The characteristics of the studies included are summarised in Table 1. There is 1 randomised controlled trial, 2 cohort studies, 1 observational and 4 cross-sectional studies. A meta-analysis could not be performed because of the heterogeneity of definition of the condition, intervention and the outcome, as well as the study designs.

Donnelly et al. [16] performed a prospective observational study of 20 postmenopausal women in 1997 with established FI and a low serum oestradiol $(<50 \mathrm{pg} / \mathrm{ml})$. Four women who had previously had a hysterectomy received an oestrogen patch for 6 months and 16 women with an intact uterus received the combination of an oestrogen patch and oral progestogen $(50 \mu \mathrm{g}$ oestradiol per $24 \mathrm{~h}$ and norethisterone acetate $1 \mathrm{mg}$ daily for 12 days per cycle (Estrapak; Ciba Geigy, Basel, Switzerland). Patients were assessed using a bowel function questionnaire (no name given), a continence grading score (adapted from Pescatori et al. [23]) and a visual analogue score (VAS; no reference given) for the impact of incontinence on daily and social activities. Anorectal physiology, which consisted of anal manometry, anal endosonography, measurement of rectal sensation, anal electrosensitivity and pudendal nerve terminal motor latency was also tested. After 6 months of the HRT, 5 out of 20 patients (25\%) reported being 
Fig. 1 Preferred Reporting Items for Systematic Reviews and Meta-Analyses (PRISMA) 2009 flow diagram showing study selection process

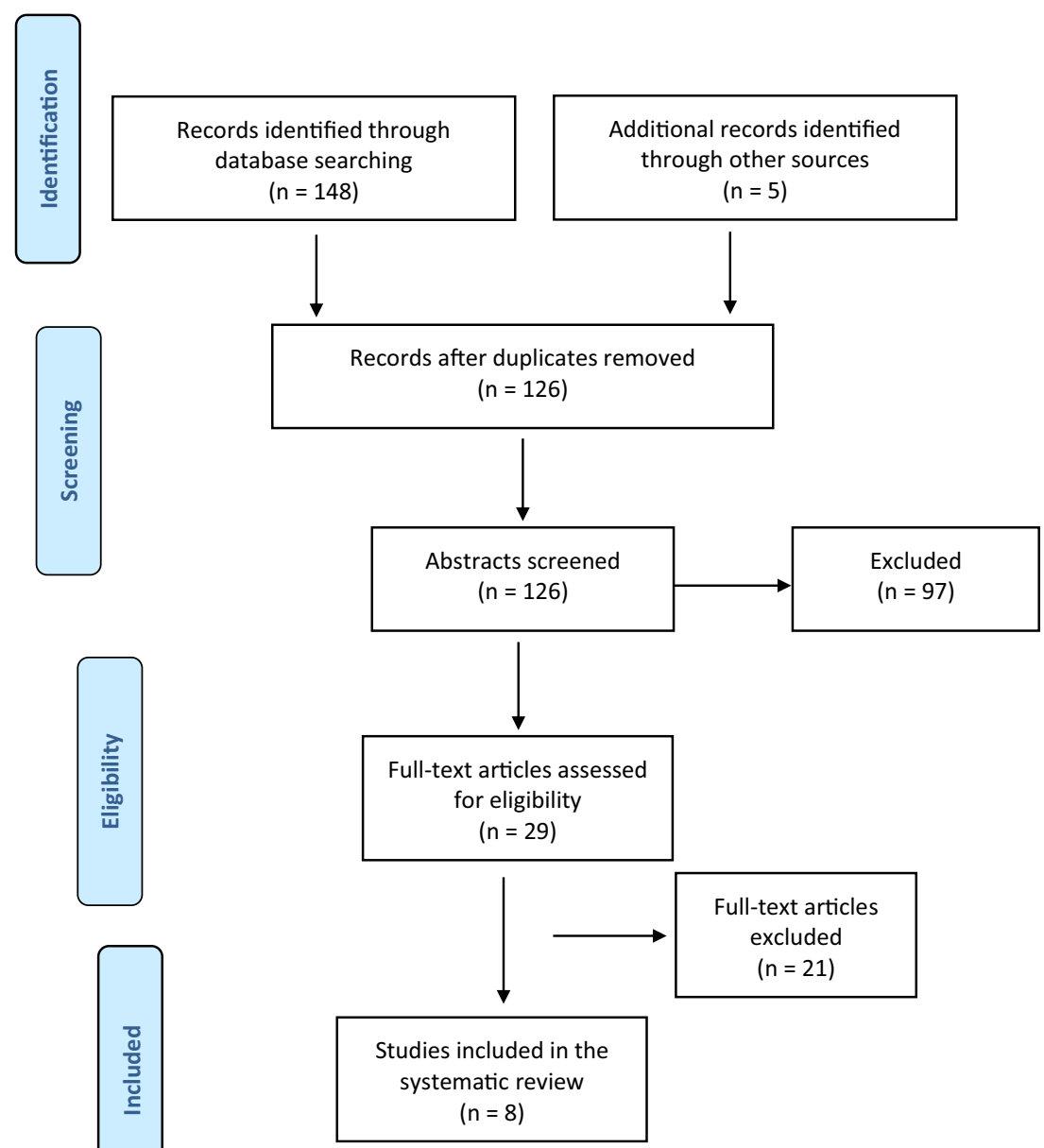

asymptomatic and a further 13 out of $20(65 \%)$ reported some improvement. The bowel function questionnaire revealed a significant reduction in the number of women suffering from flatal incontinence ( 15 women to 5 women, $p=0.004$ ), faecal staining of the underwear (10 to $2, p=0.02$ ) and defaecation urgency ( 13 to $6, p=0.05$ ), whereas a non-significant decrease in incontinence related to liquid stool (12 to 6), solid stool (6 to 3 ) and difficulty with defaecation (5 to 2 ) was demonstrated. No change was reported in the consistency of stool, requirement of digital manipulation and evacuation history. The intervention led to a significant improvement in the median scores for VAS for social activity (median score: 6 to $2, p=0.001$ ), daily activity ( 6 to $2, p=0.001$ ) and the continence score ( 15 to $8, p=0.001)$. There were significant objective improvements in mean resting anal canal pressure (33 to $40 \mathrm{mmHg}, p=0.001$ ) and mean squeeze pressure (39 to $43 \mathrm{mmHg}, p=0.03$ ) on anal manometry [16]. A significant increase in the maximum tolerated rectal volume is reported but not reflected in the numbers published in the paper $(187 \mathrm{ml}$ to $170 \mathrm{ml})$. No difference was seen in the anal canal electrosensitivity (upper 5.3 to $5.2, p=0.9$; lower 4.4 to $4.1 \mathrm{~mA} ; p=0.3$ ) or pudendal nerve terminal motor latency
(PNTML) (right 2.45 to $2.5 \mathrm{~ms}, p=0.5$; left 2.46 to 2.44 , $p=0.8$ ). Thirty percent of women included in the study were found to have a previously unreported anal sphincter defect, but there were no differences in outcomes between these subgroups.

Pinedo et al. [17] performed a double-blind randomised trial to evaluate the effectiveness of topical oestrogen compared with placebo applied to the mucosa of the anal canal. Thirty-six postmenopausal women without hormonal substitution, with a Wexner's FI score [24] of $>5$ and $<50 \%$ damage of the external sphincter were given topical estriol (Ovestin) or placebo to be applied three times a day for 6 weeks to the mucosa of the anal canal. A Wexner score and a quality of life score (validated and accepted for the spanish language) [25, 26], which included style of life, conduct, depression and embarrassment were performed at the beginning and end of the study. A difference of $50 \%$ was considered successful as per previous research $[27,28]$ and this was used to calculate the requirement for 17 patients in each branch. Both branches had similar patient characteristics. Both groups saw a statistically significant improvement in Wexner scores (oestrogen 12 to 7 : $p=0.002$; placebo 12 to $9: p=0.013$ ), but there was no 


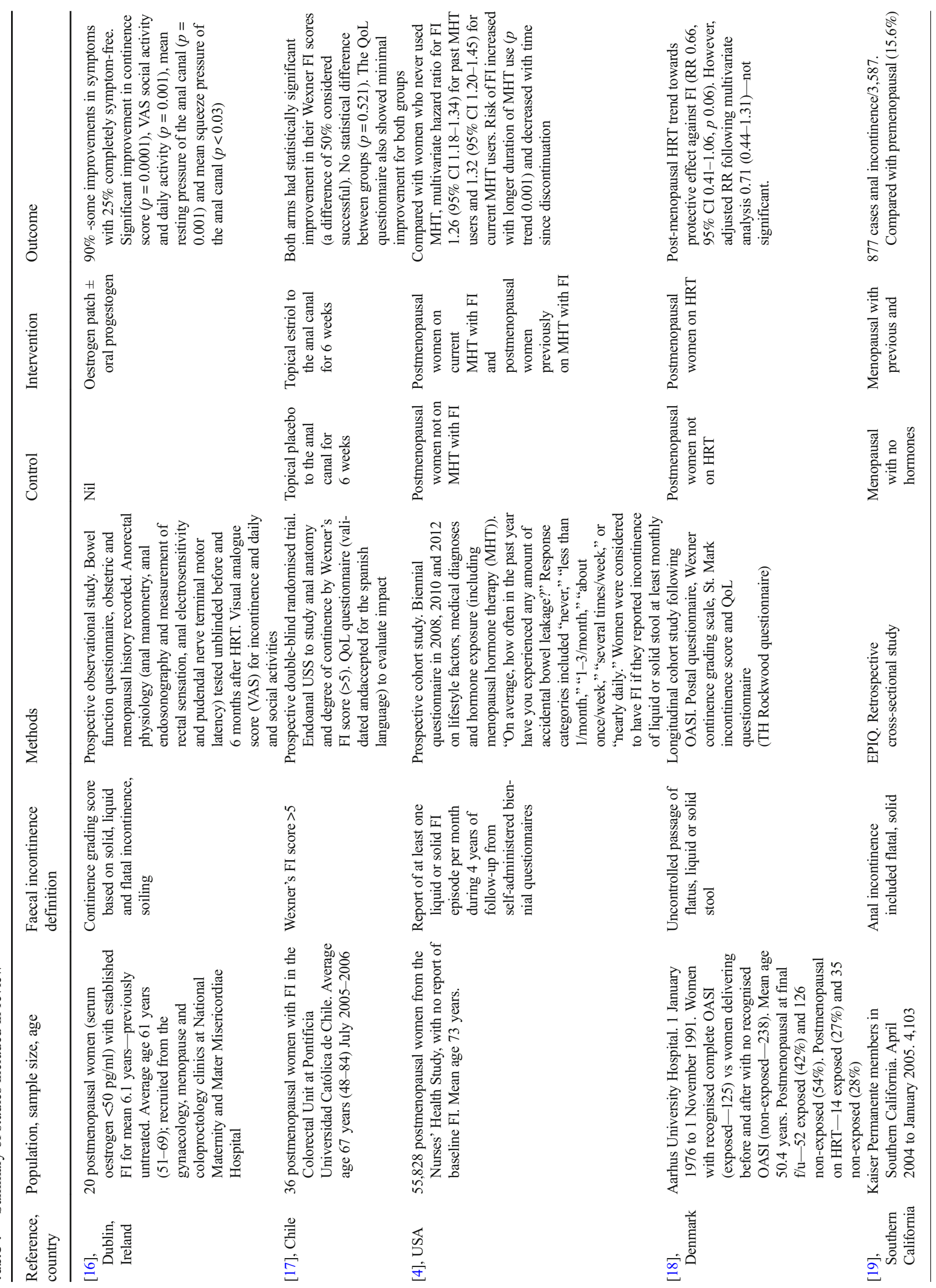




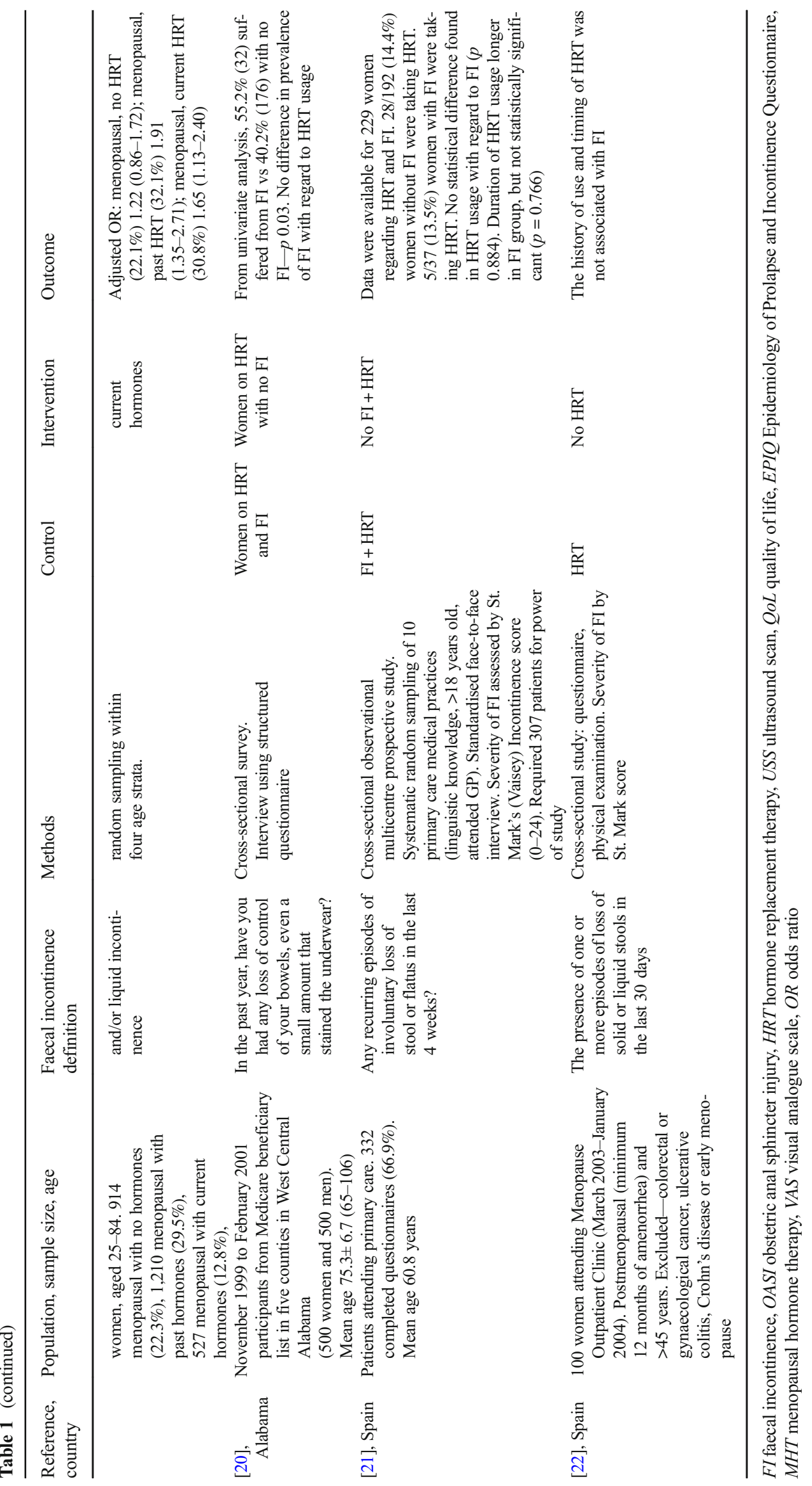


difference between the two groups $(p=0.521)$. Both groups saw minimal non-significant improvements in quality of life scores following the protocol. Five patients in the estriol group experienced pruritus ani, which did not require treatment. No other side effects or complications were reported.

Staller et al. [4] reported from The Nurses' Health Study, which was a prospective cohort of 121,701 US female nurses initiated in 1976, where biennial self-administered questionnaires were completed since its conception. In 2008, questions about FI were included in the questionnaire, allowing its association with menopausal hormone therapy (MHT) in postmenopausal women to be studied. They stated that they asked about oral MHT. After exclusions (23,393 died, 13,587 were lost to follow-up, 15,830 had no FI information, 5,737 had no MHT information, 7,325 had baseline FI), Staller et al. reported on a cohort of 55,828 nurses. Women returned questionnaires in 2008, 2010 and 2012 about lifestyle factors, medical diagnosis, FI and exposure to MHT. Lifestyle factors and medical diagnoses considered were BMI, smoking, physical activity, parity, history of cholecystectomy, diabetes, hypertension and presence of neurological disease. The definition of FI was at least one solid or liquid faecal incontinence episode monthly. The number of months used, current use and type of MHT were recorded. Because of the assumed association with hormones, the analysis included measures that were surrogates for endogenous and exogenous oestrogen exposure, including parity, age at menopause, oral contraceptive use, ovulatory duration and type of menopause (surgical, radiation, natural). Of the 55,828 postmenopausal women eligible for the analysis, 6,834 developed FI (48\% liquid, $40 \%$ solid and $12 \%$ solid and liquid). The multivariate-adjusted hazard ratios for incident FI were 1.32 (95\% CI 1.20-1.45) for current users and 1.26 (95\% CI 1.18-1.34) for past users of MHT compared with women who had never used MHT. The type of MHT altered the risk of FI in a subgroup analyses of current users: the multivariate hazard ratio was 1.37 (95\% CI $1.10-1.71$ ) for current users of combined formulations when compared with current users of oestrogen-only preparations. Women who were current users of MHT were younger at menopause, less likely to be obese or have diabetes and more likely to have had a surgically/radiation-induced menopause and to have used oral contraception. A longer duration of MHT increased the risk of FI with a multivariate adjusted risk of 1.22 (95\% CI 1.13-1.31) for 1-5 years of use, 1.24 (95\% CI $1.15-1.35)$ for $6-10$ years of use, and 1.32 (95\% CI $1.23-$ $1.41)$ for $>10$ years' use $\left(p_{\text {linear trend }}<0.0001\right)$. The risk appears to return to baseline after $>2$ years of discontinuation of MHT [4].

Lawrence et al. [19] performed a cross-sectional study of patients enrolled in a health care plan in California (Kaiser Permanente), using the Epidemiology of Prolapse and Incontinence Questionnaire (EPIQ) [29] to compare the presence of anal incontinence (AI) in postmenopausal women with different oral hormone therapy usage versus premenopausal women. Out of 4,103 women available for analysis, 914 were postmenopausal with no hormones (22.3\%), 1,210 were postmenopausal women who had used hormones in the past $(29.5 \%)$ and 527 were on hormone therapy $(12.8 \%)$ at the time of the study. There were a total of 877 cases of AIdefined as leakage of gas as well as solid and liquid stooland they found that hormone therapy in postmenopausal women increased the risk of AI. $15.6 \%$ of premenopausal women had AI compared with $22.1 \%$ who were menopausal with no hormone therapy (adjusted OR 1.22 [0.86-1.72]), $32.1 \%$ who had had hormone therapy in the past (1.91 $[1.35-2.71])$ and $30.8 \%$ who were currently on hormone therapy (1.65 [1.13-2.40]).

Goode et al. [20] performed a similar cross-sectional survey on Medicare beneficiaries (Alabama), asking "In the past year, have you had any loss of control of your bowels, even a small amount, that stained the underwear?" A univariate analysis showed that significantly more $(p=0.03)$ women with FI were using oestrogen replacement therapy $(55.2 \%)$ than those who did not have FI (40.2\%), but in a multivariate analysis, it was found to be non-significant ( $p$ value not recorded).

Soerensen et al. [18] performed a longitudinal prospective cohort study in women who had undergone primary OASI repair identified from the Danish National Registry compared with controls on either side of the birth register. A questionnaire was sent out in 1989, 1992 and 2007. FI was defined as uncontrolled passage of flatus, liquid or solid stool and was graded by severity using the Wexner continence grading scale [24], the St. Mark incontinence score [30] and a QoL questionnaire (TH Rockwood Questionnaire [26]). Postmenopausal oral hormone therapy was included to look at long-term risk in these patients and showed a trend towards some protective effect against FI (relative risk [RR] 0.66, 95\% CI $0.41-1.06, p 0.06$ ). The adjusted RR following multivariate analysis was not significant at 0.71 (95\% CI 0.44-1.31).

De Oliveira et al. [22] performed a cross-sectional study of 100 postmenopausal women in 2003-2004 attending the Menopause Outpatient Clinic of the State University of Campinas (Campinas, Spain). The definition of FI was the presence of one or more episodes of loss of solid or liquid stool in the last 30 days and the St. Mark score was used to assess severity. No association between hormone therapy and FI was found.

Bohle et al. [21] performed a cross-sectional observational multicentre study where 322 patients, selected at random, were questioned while attending a primary care setting (Barcelona, Spain). FI was defined as the involuntary loss of flatus or liquid/solid stool occurring during the last 4 weeks. The severity of FI was assessed using the St. Mark (Vaizey) Incontinence score (0-24) [30]. Data were available for 229 postmenopausal women regarding hormone therapy and FI. Of these, 28 out of 192 (14.4\%) women without FI were 
Table 2 Revised Cochrane risk-of-bias tool for randomised trials (RoB 2)

\begin{tabular}{|c|c|c|c|c|c|c|c|}
\hline RCT & $\begin{array}{l}\text { Bias from the } \\
\text { randomisation } \\
\text { process }\end{array}$ & $\begin{array}{l}\text { Effect of } \\
\text { assignment to } \\
\text { intervention }\end{array}$ & $\begin{array}{l}\text { Effect of adhering } \\
\text { to intervention }\end{array}$ & $\begin{array}{l}\text { Bias due to } \\
\text { missing outcome } \\
\text { data }\end{array}$ & $\begin{array}{l}\text { Bias in } \\
\text { measurement of the } \\
\text { outcome }\end{array}$ & $\begin{array}{l}\text { Bias in selection of } \\
\text { reported result }\end{array}$ & $\begin{array}{l}\text { Overall } \\
\text { risk of bias }\end{array}$ \\
\hline $\begin{array}{r}\text { Pinedo } \\
\text { et al. } \\
{[17]}\end{array}$ & Low & Some concerns & Low & Low & Low & Low & $\begin{array}{l}\text { Some } \\
\text { concerns }\end{array}$ \\
\hline
\end{tabular}

taking hormone therapy and 5 out of 37 (13.5\%) women with FI were taking hormone therapy. No statistical difference was found in hormone therapy usage with regard to FI ( $p=0.884)$.

Eight studies were included in this systematic review to assess the effect of exogenous oestrogen on FI in postmenopausal women. The studies indicated variable results, from some benefit to worsening of FI. All the studies included had a risk of bias and were not found to be of high quality on the Cochrane risk-of-bias tool and Newcastle-Ottawa scale (Tables 2, 3).

The first paper, published in 1997, was a small observational study with neither a comparison group nor blinding and therefore had a high risk of bias [16]. Objective and subjective approaches to patient outcomes were assessed and the testing was very thorough. The intervention was not uniform, as some patients received combined oestrogen and progesterone replacement, whereas some had oestrogen alone but no comments were made as to whether this altered the outcome. The authors reported that all women completed the study, but did not specifically comment on compliance to medications. No information was given on the two patients who did not improve. The RCT performed [17] demonstrated "some concerns" when assessed using the Cochrane risk-of-bias tool [14]. It was double-blinded and had a robust randomisation method; however, it did not follow the "intention-to-treat" analysis (Table 2) and there is no record of compliance to medication. The nurses cohort study [4] has large numbers and is prospective; however, the population is selective (nurses only) and there is a risk of bias owing to selfcompletion of the questionnaires. It controlled for confounders associated with FI and other exposure to oestrogen. Initially, it was stated that the hormone therapy recorded in this study consisted of oral preparations only, although the authors later stated that they could not be sure that there were not some that were wrongly classified and that some of the participants were using topical preparations. The study by Soerensen et al. was not designed to look specifically at hormone therapy and postmenopausal FI; thus, although useful information can be taken from it, the study design cannot be assessed on this basis [18]. The remaining studies were crosssectional surveys with inherent bias and some were not designed to explore faecal incontinence as the main outcome [19-21].

\section{Discussion}

We believe that this is currently the only review collating all the evidence available related to the impact of oestrogen on FI for postmenopausal women. The role of oestrogen therapy (vaginal, anal, systemic) in the treatment of FI in postmenopausal remains unclear because of limited high-quality data, but there is biological plausibility.
Table 3 Newcastle-Ottawa Quality Assessment Scale for Cohort Studies

\begin{tabular}{lll}
\hline Study reference & $\begin{array}{l}\text { Soerensen et al. } \\
{[18]}\end{array}$ & \begin{tabular}{l} 
Staller et al. [4] \\
\hline Study design
\end{tabular} \\
$\begin{array}{lll}\text { Cohort } & \text { Prospective } \\
\text { cohort }\end{array}$ \\
$\begin{array}{l}\text { Representativeness of the exposed cohort } \\
\text { Selection of the non-exposed cohort }\end{array}$ & 0 & 0 \\
Ascertainment of exposure & 1 & 1 \\
Demonstration that the outcome of interest was not present at the start of & 0 & 0 \\
$\quad$ the study & 0 & 1 \\
Comparability on the basis of the design or analysis & 0 & 2 \\
Assessment of outcome & 0 & 0 \\
Adequate follow-up period & 1 & 0 \\
Adequacy of follow-up & 1 & 0 \\
Overall & 3 out of 9 & 4 out of 9 \\
\hline
\end{tabular}


The mechanism suggested for the improvement reported in the first study by Donnelly et al. [16] was increased resting pressure of the internal sphincter due to the improved functionality related to oestrogen causing alteration of collagen and elastic content of the pelvic floor. The subjective beneficial effects observed may have been related to an actual improvement in symptoms, but could also have been due to improved general wellbeing owing to increased circulating oestrogen from systemic administration and it is difficult to separate these effects [16]. The next study [17] found that topical anal oestrogens improved symptoms of FI; however, the placebo group also improved, highlighting a complex pathophysiology for FI with potential psychological overlay altering the patients' perception of the condition and therefore altering the subjective outcomes. In contrast to these first two studies, in 2017, the large prospective cohort study [4] gave a hypothesis of oestrogen-mediated loss of connective tissue from the internal sphincter and levator ani to explain the increased FI with current and previous oestrogen use. The increased effect seen with combination therapy is attributed to progestin, causing both increased oestrogen receptors on the anorectum and a direct effect on oestrogen at a nuclear level. It is difficult to establish, in this particular study, whether exogenous oestrogen increases the risk of FI or whether women taking exogenous oestrogen are those who are affected most by both menopausal symptoms and FI and may have lower natural oestrogen levels. Although all the studies discussed add value to this systematic review, Staller et al.'s finding of increased risk of FI with oestrogen use is potentially a key finding that should be investigated promptly [4]. Faecal incontinence could be an under-reported but considerable side effect of the widespread use of hormone therapy in postmenopausal women.

With the ageing population worldwide, FI is a growing problem that needs to be addressed [2]. There is no definitive answer that we can give as to whether oestrogen therapy is helpful or harmful with regard to FI in postmenopausal women, but this review has certainly indicated the scope for further research in this field. Based on biological plausibility and lack of current studies establishing the role of oestrogen therapy on FI, high-quality studies examining the impact of oestrogen on FI are warranted. Standard definitions would aid our field in interpreting the impact of interventions on FI.

In conclusion, this review has highlighted the paucity of good-quality evidence in this area. We would suggest that a further randomised controlled trial (RCT) might be required to draw a valid conclusion. However, the challenges to this would be how to define faecal incontinence, in particular, the frequency of incontinence that is appropriate, and how much of an improvement is classed as a "success". Using any systemic hormone therapy is associated with risks and an RCT to assess the effect of systemic oestrogen on faecal incontinence may be technically and ethically difficult to design; vaginal oestrogen might be more appropriate.

Acknowledgements We would like to thank Derick Yates (Evidence Based Practice Tutor) of Birmingham Women's and Children's Library and Knowledge Service for his assistance in writing the search strategies and conducting the literature searches.

Authors' contributions F.L.B.: review of papers, manuscript writing/ editing; B.Z.F.S.: review of papers, manuscript writing/editing; P.L.: conception of the idea, project development, review of papers, manuscript editing.

\section{Compliance with ethical standards}

Conflicts of interest None.

Open Access This article is licensed under a Creative Commons Attribution 4.0 International License, which permits use, sharing, adaptation, distribution and reproduction in any medium or format, as long as you give appropriate credit to the original author(s) and the source, provide a link to the Creative Commons licence, and indicate if changes were made. The images or other third party material in this article are included in the article's Creative Commons licence, unless indicated otherwise in a credit line to the material. If material is not included in the article's Creative Commons licence and your intended use is not permitted by statutory regulation or exceeds the permitted use, you will need to obtain permission directly from the copyright holder. To view a copy of this licence, visit http://creativecommons.org/licenses/by/4.0/.

\section{References}

1. Rothbarth J, Bemelman WA, Meijerink WJ, et al. What is the impact of fecal incontinence on quality of life? Dis Colon Rectum. 2001;44(1):67-71.

2. Ng KS, Sivakumaran Y, Nassar N, Gladman MA. Fecal incontinence: community prevalence and associated factors - a systematic review. Dis Colon Rectum. 2015;58(12):1194-209.

3. Bharucha AE, Zinsmeister AR, Locke GR, et al. Risk factors for fecal incontinence: a population-based study in women. Am J Gastroenterol. 2006;101(6):1305-12.

4. Staller K, Townsend MK, Khalili H, et al. Menopausal hormone therapy is associated with increased risk of fecal incontinence in women after menopause. Gastroenterology. 2017;152(8):19151921.e1.

5. Haadem K, Ling L, Fernö M, Graffner H. Estrogen receptors in the external anal sphincter. Am J Obstet Gynecol. 1991;164(2):609-10.

6. Oettling G, Franz HB. Mapping of androgen, estrogen and progesterone receptors in the anal continence organ. Eur J Obstet Gynecol Reprod Biol. 1998;77(2):211-6.

7. Parés D, Iglesias M, Pera M, et al. Expression of estrogen and progesterone receptors in the anal canal of women according to age and menopause. Dis Colon Rectum. 2010;53(12):1687-91.

8. Rizk DE, Helal TE, Mason N, Berg B. Non-evidence of estrogen receptors in the rectal mucosa. Int Urogynecol J Pelvic Floor Dysfunct. 1998;9(3):136-9.

9. Knudsen UB, Laurberg S, Danielsen CC. Influence of bilateral oophorectomy and estrogen substitution on the striated anal sphincter in adult female rats. Scand J Gastroenterol. 1991;26(7):731-6. 
10. Xu J, Bartoces M, Neale AV, Dailey RK, Northrup J, Schwartz KL. Natural history of menopause symptoms in primary care patients: a MetroNet study. J Am Board Fam Pract. 2005;18(5):374-82.

11. Van Voorhis BJ. Genitourinary symptoms in the menopausal transition. Am J Med. 2005;118(Suppl 12B):47-53.

12. Perrotta C, Aznar M, Mejia R, Albert X, Ng CW. Oestrogens for preventing recurrent urinary tract infection in postmenopausal women. Cochrane Database Syst Rev. 2008;2:CD005131.

13. Cody JD, Jacobs ML, Richardson K, Moehrer B, Hextall A. Oestrogen therapy for urinary incontinence in post-menopausal women. Cochrane Database Syst Rev. 2012;10:CD001405.

14. RoB 2: A revised Cochrane risk-of-bias tool for randomized trials. https://methods.cochrane.org/bias/resources/rob-2-revisedcochrane-risk-bias-tool-randomized-trials

15. Wells G, Shea B, O'Connell D, Peterson J, Welch V, Losos M, Tugwell P. The Newcastle-Ottawa Scale (NOS) for assessing the quality of nonrandomized studies in meta-analysis, 2000. http:// www.ohri.ca/PROGRAMS/CLINICAL EPIDEMIOLOGY/ OXFORD.ASP

16. Donnelly V, O'Connell PR, O'Herlihy C. The influence of oestrogen replacement on faecal incontinence in postmenopausal women. Br J Obstet Gynaecol. 1997;104(3):311-5.

17. Pinedo G, García E, Zárate AJ, León F, Bellolio F, Molina ME, et al. Are topical oestrogens useful in faecal incontinence? Double-blind randomized trial. Colorectal Dis. 2009;11(4):390-3.

18. Soerensen MM, Buntzen S, Bek KM, Laurberg S. Complete obstetric anal sphincter tear and risk of long-term fecal incontinence: a cohort study. Dis Colon Rectum. 2013;56(8):992-1001.

19. Lawrence JM, Lukacz ES, Nager CW, Hsu JW, Luber KM. Prevalence and co-occurrence of pelvic floor disorders in community-dwelling women. Obstet Gynecol. 2008;111(3):67885 .

20. Goode PS, Burgio KL, Halli AD, et al. Prevalence and correlates of fecal incontinence in community-dwelling older adults. J Am Geriatr Soc. 2005;53(4):629-35.
21. Bohle B, Belvis F, Vial M, et al. Menopause and obstetric history as risk factors for fecal incontinence in women. Dis Colon Rectum. 2011;54(8):975-81.

22. De Oliveira SC, Pinto-Neto AM, Conde DM, Góes JR, Santos-Sá $\mathrm{D}$, Costa-Paiva L. Fecal incontinence in postmenopausal women: prevalence, severity and associated factors. Arq Gastroenterol. 2006;43(2):102-6.

23. Pescatori M, Anastasio G, Bottini C, Mentasti A. New grading and scoring for anal incontinence. Evaluation of 335 patients. Dis Colon Rectum. 1992;35(5):482-7.

24. Jorge JM, Wexner SD. Etiology and management of fecal incontinence. Dis Colon Rectum. 1993;36(1):77-97.

25. Minguez M, Garrigues V, Soria MJ, Andreu M, Mearin F, Clave P. Adaptation to Spanish language and validation of the fecal incontinence quality of life scale. Dis Colon Rectum. 2006;49(4):490-9.

26. Rockwood TH, Church JM, Fleshman JW, et al. Fecal incontinence quality of life scale: quality of life instrument for patients with fecal incontinence. Dis Colon Rectum. 2000;43(1):9-16 discussion 167.

27. Pinedo G, Vaizey CJ, Nicholls RJ, Roach R, Halligan S, Kamm MA. Results of repeat anal sphincter repair. Br J Surg. 1999;86(1): 66-9.

28. Vaizey CJ, Norton C, Thornton MJ, Nicholls RJ, Kamm MA. Long-term results of repeat anterior anal sphincter repair. Dis Colon Rectum. 2004;47(6):858-63.

29. Lukacz ES, Lawrence JM, Buckwalter JG, Burchette RJ, Nager $\mathrm{CW}$, Luber KM. Epidemiology of prolapse and incontinence questionnaire: validation of a new epidemiologic survey. Int Urogynecol J Pelvic Floor Dysfunct. 2005;16(4):272-84.

30. Vaizey CJ, Carapeti E, Cahill JA, Kamm MA. Prospective comparison of faecal incontinence grading systems. Gut. 1999;44(1):7780 .

Publisher's note Springer Nature remains neutral with regard to jurisdictional claims in published maps and institutional affiliations. 